\title{
A competitive dual-label time-resolved fluoroimmunoassay for the simultaneous determination of chloramphenicol and ractopamine in swine tissue
}

\author{
ZHANG Zhen ${ }^{1}$, LIU JingFu ${ }^{*}$, YAO Yan ${ }^{2} \&$ JIANG GuiBin ${ }^{1}$ \\ ${ }^{1}$ State Key Laboratory of Environmental Chemistry and Ecotoxicology, Research Center for Eco-Environmental Sciences, Chinese Academy of \\ Sciences, Beijing 100086, China; \\ ${ }^{2}$ Department of Isotope, China Institute of Atomic Energy, Beijing 102413, China
}

Received September 1, 2010; accepted November 10, 2010; published online April 13, 2011

\begin{abstract}
A novel dual-label time-resolved fluoroimmunoassay method was developed for the simultaneous determination of chloramphenicol (CAP) and ractopamine (RAC) residues in 18 swine tissue samples, using anti-CAP and anti-RAC monoclonal antibodies labeled with europium $\left(\mathrm{Eu}^{3+}\right)$ and samarium $\left(\mathrm{Sm}^{3+}\right)$, respectively. The detection limits for CAP and RAC were 0.06 and 0.25 $\mathrm{ng} / \mathrm{g}$. The recovery from swine muscle samples was $102 \%-121 \%$ for CAP at spiking levels of $0.1-5 \mathrm{ng} / \mathrm{g}$, and $69.8 \%-85.8 \%$ for RAC at spiking levels of $1-10 \mathrm{ng} / \mathrm{g}$. The results obtained from the swine tissue samples using this method showed good agreement with those obtained using ELISA and GC-MS, with correlation coefficients $(R)$ between 0.92-0.98.
\end{abstract}

dual-label time-resolved fluoroimmunoassay, chloramphenicol, ractopamine, residue, swine tissue

Citation: Zhang Z, Liu J F, Yao Y, et al. A competitive dual-label time-resolved fluoroimmunoassay for the simultaneous determination of chloramphenicol and ractopamine in swine tissue. Chinese Sci Bull, 2011, 56: 1543-1547, doi: 10.1007/s11434-011-4412-4

Chloramphenicol (CAP) is a broad spectrum antibiotic often used in veterinary practice for the prevention and treatment of many bacterial diseases. However, continual use in pigs may result in a build-up of CAP residues in tissue, and this may have toxic effects on consumers $[1,2]$. Therefore, the administration of CAP has been banned in many countries including the EU, the USA and China. Techniques such as liquid chromatography (LC) [3], liquid chromatographymass spectrometry (LC-MS) [4], LC-MS/MS [5,6], and others [7-10] are currently used to determine CAP levels.

Ractopamine (RAC) is a $\beta_{2}$-adrenoceptor agonist approved for use in finishing swine to improve weight gain, lean muscle mass and feed efficiency [11]. It is not permitted for use in food-producing animals in the EU and China because of the potential danger to humans [12,13]. Therefore, developing sensitive analytical methods for monitoring the levels of RAC residues in animal-derived food stuffs is

*Corresponding author (email: jfliu@ @rcees.ac.cn) of great importance. The currently available methods for RAC determination are mainly based on LC-MS [14-16].

Because CAP and RAC are strictly controlled and widely tested for animal-derived foods, it is of interest to develop methods for the simultaneous determination of these two analytes. To date, most multi-analyte assays for veterinary drug residues have focused on structurally related compounds [17-22], and no method has been developed for the simultaneous detection of different drug classes in animal tissue samples.

In this study, a novel dual-label time-resolved fluoroimmunoassay (TRFIA) assay was developed for the simultaneous detection of CAP and RAC in swine tissue using anti-CAP and anti-RAC monoclonal antibodies (Mabs) labeled with europium $\left(\mathrm{Eu}^{3+}\right)$ and samarium $\left(\mathrm{Sm}^{3+}\right)$, respectively. After reaction with the labeled Mabs [23,24] and treatment with co-enhancement solution, CAP and RAC in the samples were detected by measuring the fluorescence emissions of $\mathrm{Eu}^{3+}$ and $\mathrm{Sm}^{3+}$, respectively. 


\section{Materials and methods}

\subsection{Reagents and materials}

A Mab against CAP was produced according to the method of Kolosova [25], and showed insignificant cross-reactivity with other fenicol drugs such as thiamphenicol and florfenicol [10]. A Mab against RAC was obtained from the college of veterinary medicine at China Agricultural University [26]. DTTA-Eu ${ }^{3+}$ and DTTA-Sm ${ }^{3+}$ were purchased from Tianjin Radio-Medical Institute (Tianjin, China). CAP, RAC, ovalbumin (OVA), and bovine serum albumin (BSA) were obtained from Sigma-Aldrich (St. Louis, MO, USA). Transparent 96-well micro-titration strips were purchased from Nunc (Roskilde, Denmark). Sephadex 6B and G-50 were purchased from Pharmacia (Uppsala, Sweden). Commercial ELISA kits for determining RAC and CAP residues in animal tissue were purchased from Wanger $\mathrm{Bi}$ ology Co. Ltd (Beijing, China). Other reagents were of analytical quality and supplied by Beijing Reagent Corporation (Beijing, China).

\subsection{Labeling of Mab with europium and samarium chelate}

The Mabs against CAP and RAC were dialyzed twice in coating buffer $\left(0.1 \mathrm{~mol} / \mathrm{L}\right.$ carbonate containing $0.05 \% \mathrm{NaN}_{3}$ and $0.9 \% \mathrm{NaCl}, \mathrm{pH} 7.8$ ) for $24 \mathrm{~h}$, then mixed with $1 \mathrm{mg}$ DTTA-Eu ${ }^{3+}$ or DTTA-Sm ${ }^{3+}$, respectively, in small brown bottles. The resulting Mab-DTTA-Eu ${ }^{3+}$ and MAb-DTTA$\mathrm{Sm}^{3+}$ chelates were purified by gel filtration on a Sephadex 6B/G-50 column $(50 \mathrm{~cm} \times 1.5 \mathrm{~cm}$, Pharmacia, Uppsala, Sweden) and eluted using washing buffer $(0.05 \mathrm{~mol} / \mathrm{L}$ Tris- $\mathrm{HCl}, \mathrm{pH} 8.0$, containing $0.9 \% \mathrm{NaCl}$ and $0.04 \%$ Tween 20). Because of their high molecular weight, the chelates were collected before any dissociated $\mathrm{Eu}^{3+}$ and $\mathrm{Sm}^{3+}$. After adding $0.1 \%$ BSA and $0.04 \% \mathrm{NaN}_{3}$, part of the purified chelate solution could be stored at $-20^{\circ} \mathrm{C}$ for up to a year. Those used in this study were maintained at $4^{\circ} \mathrm{C}$. The molar ratio of labeled $\mathrm{Eu}^{3+}$ and $\mathrm{Sm}^{3+}$ to Mab was determined by fluorescence measurement at $280 \mathrm{~nm}\left(A_{280}\right)$ and calculated using the equation: $Y=C\left(\left[\mathrm{Eu}^{3+}\right], \mu \mathrm{mol} / \mathrm{L}\right) / C(\mathrm{Mab}, \mu \mathrm{mol} / \mathrm{L})$.

\subsection{Time-resolved fluoroimmunoassay procedure}

The coating antigens (OVA-CAP and OVA-RAC) were mixed with coating buffer, pipetted into microtiter plate strips (Nunc, Roskilde, Denmark) and incubated for $14 \mathrm{~h}$ at room temperature. After washing at least 3 times with washing buffer, the strips were blocked with blocking buffer $(0.05 \mathrm{~mol} / \mathrm{L}$ Tris- $\mathrm{HCl}$, containing $0.5 \% \mathrm{BSA}, 0.9 \%$ $\mathrm{NaCl}$ and $0.04 \% \mathrm{NaN}_{3}, \mathrm{pH} 8.0$ ) at $37^{\circ} \mathrm{C}$ for $1 \mathrm{~h}$. Test samples, or a series of standards, were then added to the wells along with the $\mathrm{Eu}^{3+}$-labeled or $\mathrm{Sm}^{3+}$-labeled Mabs diluted at the appropriate concentrations in dilution buffer $(0.05 \mathrm{~mol} / \mathrm{L}$ Tris- $\mathrm{HCl}$ containing $0.9 \% \mathrm{NaCl}, \mathrm{pH} 8.0$ ). Finally, the co-enhancement solution $(0.1 \mathrm{~mol} / \mathrm{L}$ potassium biphthalate-acetic acid buffer containing $15 \mu \mathrm{mol} / \mathrm{L} \beta$-naphthoyltrifluoroacetone and $0.1 \%$ Triton $\mathrm{X}-100$ ) was added to each well, and the fluorescence signal measured using a VICTOR $^{2}$ multilabel counter (Perkin-Elmer Wallac, Turku, Finland). The fluorescence of $\mathrm{Eu}^{3+}$ was measured at an excitation wavelength of $340 \mathrm{~nm}$ and an emission wavelength of $615 \mathrm{~nm}$, with a delay time of $0.40 \mathrm{~ms}$ and a cycle period of $1.0 \mathrm{~ms} . \mathrm{Sm}^{3+}$ fluorescence was measured at an excitation wavelength of $340 \mathrm{~nm}$ and an emission wavelength of 642 $\mathrm{nm}$, with a delay time of $0.05 \mathrm{~ms}$ and a cycle period of 0.10 $\mathrm{ms}$.

\subsection{Standard curve}

A series of mixed standards with concentrations (CAP/ RAC) of $0 / 0,0.05 / 0.25,0.1 / 0.5,0.25 / 1.25,0.5 / 2.5,1 / 5$, $2.5 / 12.5,5 / 25,10 / 50,20 / 100 \mathrm{ng} / \mathrm{mL}$ were prepared by diluting the CAP and RAC standards in dilution buffer. Standard curves were obtained by plotting the fluorescence intensity $(Y)$ against the logarithm of the sample concentration $(X)$ and fitted to a four-parameter logistic equation using Origin Pro7.0 (Version 7.0, Microcal, USA):

$$
Y=\left\{(A-D) /\left[1+(X / C)^{B}\right]\right\}+D,
$$

in which $A$ is the asymptotic maximum (fluorescence intensity in the absence of analytics, $S_{\max }$ ), $B$ is the curve slope at the inflection point, $C$ is the $X$ value at the inflection point (corresponding to the sample concentration that reduces $S_{\max }$ to $50 \%, \mathrm{IC}_{50}$ ), and $D$ is the asymptotic minimum (background signal).

\subsection{Sample pretreatment}

Five grams of homogenized swine muscle was mixed with $15 \mathrm{~mL}$ of a solution containing acetonitrile and $0.01 \mathrm{~mol} / \mathrm{L}$ $\mathrm{HCl}(84 / 16, V / V)$, vortexed for $1 \mathrm{~min}$ and centrifuged for 10 $\min$ at $5000 \times g$. Three milliliters of the resulting supernatant was mixed with $2 \mathrm{~mL}$ of sodium borate buffer $(\mathrm{pH} 10.3)$ using a vortex. The mixture was then mixed with acetic ether and allowed to stand for $10 \mathrm{~min}$. The upper fraction was then separated, evaporated to dryness, and the residue dissolved in $1 \mathrm{~mL}$ of dilution buffer before being defatted using n-hexane. After centrifuging for $10 \mathrm{~min}$ at $8000 \times \mathrm{g}$, the lower fraction $(100 \mu \mathrm{L})$ was pipetted into the wells for analysis.

\subsection{Validation using other methods}

The new experimental method was verified using ELISA and GC-MS. ELISAs were conducted using commercially available ELISA kits (Wanger biology Co. Ltd, China) as previously described [14]. GC-MS was performed as previously described [27] using an Agilent (Palo Alto, CA, USA) model 6890 GC, a model 5973 mass-selective detector, and an HP-5 capillary column $(0.25 \mathrm{~mm} \times 30 \mathrm{~m} \times 0.25 \mu \mathrm{m})$. 


\section{Results and discussion}

\subsection{Optimization of detection conditions}

TRFIA performance depends on several experimental factors, including a suitable molar ratio of the labeled $\mathrm{Eu}^{3+}$ or $\mathrm{Sm}^{3+}$ to $\mathrm{Mab}$, appropriate ratios of antigen and tracer (labeled Mab) and the addition ratio $\left(V_{\text {tracer }} / V_{\text {sample }}\right)$, the buffer species used, and the immunoassay reaction time. These parameters were optimized for both CAP and RAC using standard mixtures, and $S_{\max } / \mathrm{IC}_{50}$ as the major parameter to estimate the sensitivity. The results showed that the labeling ratio of $\mathrm{Eu}^{3+}$ : anti-CAP Mab was 4/1, and $\mathrm{Sm}^{3+}$ : anti-RAC Mab was 6/1. The greatest sensitivity was obtained using a tracer dilution (volume of labeled Mab:volume of dilution buffer) of $1 / 200$ for CAP and 1/40 for RAC, an addition ratio of 100/100, antigen dilution ratios (volume of antigens : volume of coating buffer) of 6.7/20000 for RACovalbumin and 45/20000 for CAP-ovalbumin, and an incubation time of $1 \mathrm{~h}$.

It is generally believed that the greater the number of $\mathrm{Eu}^{3+}$ or $\mathrm{Sm}^{3+}$ bound to each Mab, the stronger the fluorescence signal obtained. However, we found that the immunoreactivity and stability of the bound chelate decreased at labeling ratios $\left(\mathrm{Eu}^{3+}: \mathrm{Mab}\right.$ and $\left.\mathrm{Sm}^{3+}: \mathrm{Mab}\right)$ higher than 20 . The greatest sensitivity was obtained with labeling ratios between 4 and 10. Probably it is because higher ratios may weaken the affinity of the Mabs for the haptens. We also found that the fluorescence signals obtained after dual-labeling or single-labeling were not significantly different, suggesting that the dual-labeled method can be used to determine CAP and RAC levels without sacrificing sensitivity.

\subsection{Analytical performance}

Figure 1 shows the standard curves obtained from 10 separate assays. The limits of detection (LOD) that gave a $10 \%$ inhibition of the maximal $\mathrm{Eu}^{3+}$ and $\mathrm{Sm}^{3+}$ fluorescence were $0.06 \mathrm{ng} / \mathrm{g}$ for CAP and $0.25 \mathrm{ng} / \mathrm{g}$ for RAC. Muscle samples lacking the analytes were spiked with $0.1 / 1,1 / 5,5 / 10 \mathrm{ng} / \mathrm{g}$ of CAP/RAC, before analysis. The results, shown in Table 1 , indicated that the recovery ranged from $102 \%-121 \%$ for CAP and $69.8 \%-85.8 \%$ for RAC. The intra-assay variation was $12 \%-17 \%$ for CAP and $10 \%-16 \%$ for RAC, while the inter-assay variation was $17 \%-20 \%$ for CAP and $17 \%-21 \%$ for RAC. These values are acceptable for the detection of $\mathrm{CAP}$ and RAC residues.

To further evaluate the applicability of the proposed method, 18 swine muscle samples were spiked with random

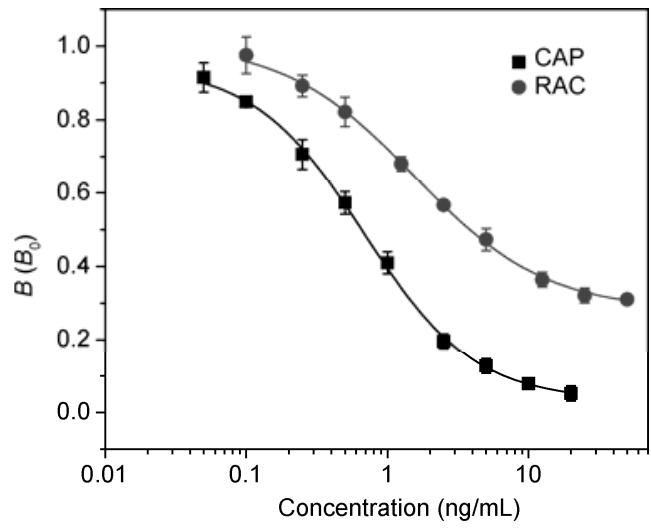

Figure 1 Typical standard curves for CAP and RAC. Each point represents the mean \pm standard deviation of three replicates.

Table 1 Recovery of CAP and RAC from fortified blank swine muscle samples

\begin{tabular}{ccccc}
\hline Analyte & $\begin{array}{c}\text { Added } \\
(\mathrm{ng} / \mathrm{g})\end{array}$ & $\begin{array}{c}\text { Recovery } \\
(\%, n=4)\end{array}$ & $\begin{array}{c}\text { Intra-assay } \\
(\mathrm{CV} \%, n=4)\end{array}$ & $\begin{array}{c}\text { Inter-assay } \\
(\mathrm{CV} \%, n=3)\end{array}$ \\
\hline \multirow{3}{*}{ CAP } & 0.1 & 121 & 17 & 20 \\
& 1 & 115 & 16 & 17 \\
\hline \multirow{2}{*}{ RAC } & 5 & 102 & 12 & 18 \\
& 1 & 69.8 & 14 & 21 \\
& 5 & 74.6 & 16 & 19 \\
\hline
\end{tabular}

concentrations of CAP and RAC and measured using ELISA, GC-MS and TRFIA. As shown in Figure 2, the results of TRFIA showed good agreement with those obtained using ELISA and GC-MS, with correlation coefficients $(R)$ in the range of 0.92-0.98. Thus, dual-lable TRFIA is a reliable method for the simultaneous determination of CAP and $\mathrm{RAC}$ residues in swine tissue.

\section{Conclusion}

In this study, we established a simple and sensitive TRFIA method for the simultaneous determination of CAP and RAC levels in swine tissue. This is the first report of a TRFIA method that can be used to for the simultaneous detection of drug residues belonging to different chemical classes. This novel procedure yielded significant reductions in assay time, and showed good correlation with ELISA and GC-MS. It is expected that this approach will allow the rapid detection and measurement of different classes of chemicals in animal tissue. 

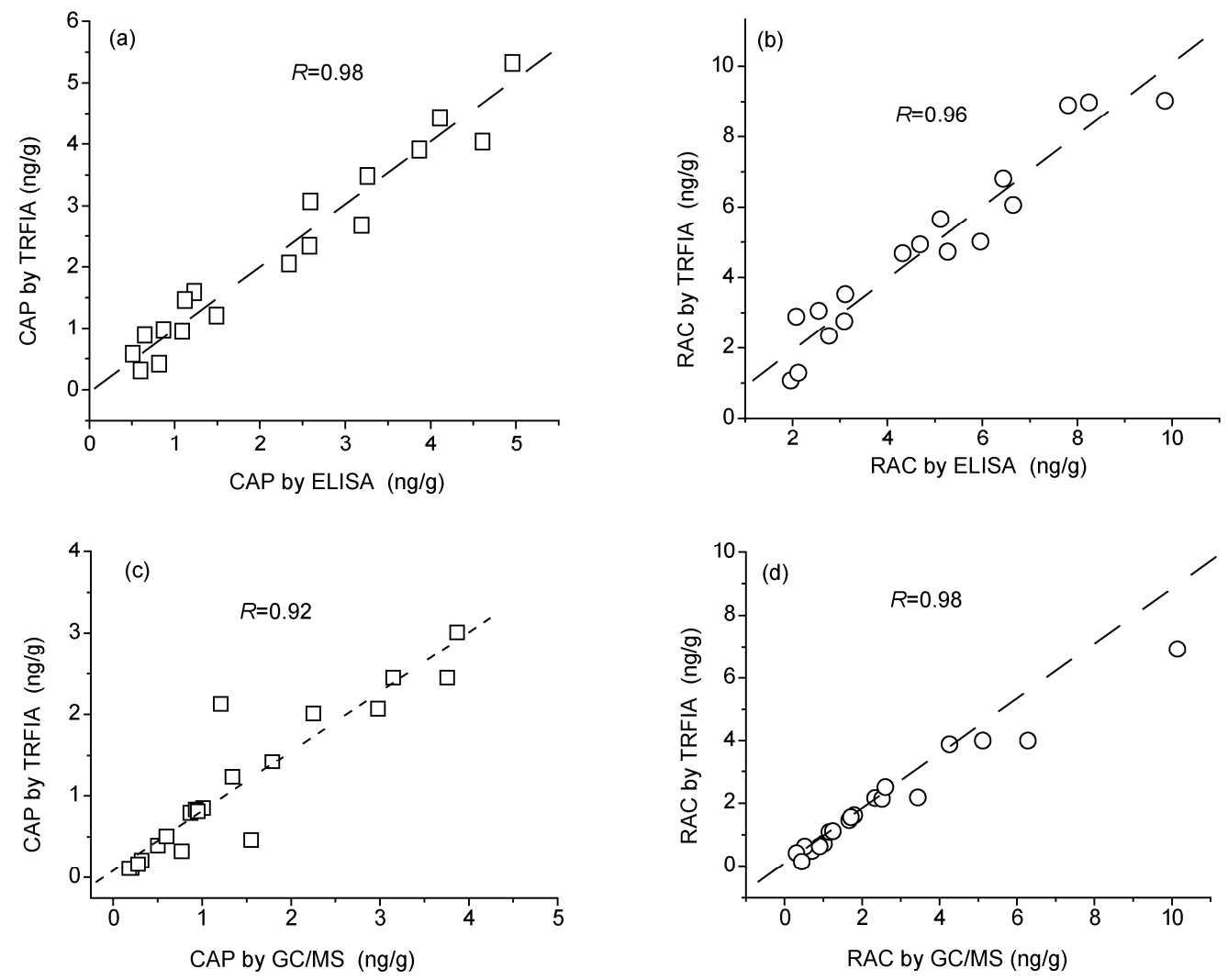

Figure 2 Correlation between TRFIA and ELISA ((a),(b)) and GC-MS ((c),(d)). $\square$, concentration of CAP;, , concentration of RAC.

This work was supported by the National Natural Science Foundation of China (21025729 and 20921063).

1 Holt D E, Bajoria R. The role of nitro-reduction and nitric oxide in the toxicity of chloramphenicol. Hum Exp Toxicol, 1999, 18: 111-118

2 Wareham D W, Wilson P. Chloramphenicol in the 21st century. Hosp Med, 2002, 63: 157-161

3 Posyniak A, Zmudzki J, Niedzielska J. Evaluation of sample preparation for control of chloramphenicol residues in porcine tissues by enzyme-linked immunosorbent assay and liquid chromatography. Anal Chim Acta, 2003, 483: 307-311

4 Masahiko T, Shigeki D, Taketoshi N. Determination of chloramphenicol residues in fish meats by liquid chromatography-atmospheric pressure photoionization mass spectrometry. J Chromatogr A, 2003, 1011: $67-75$

5 Forti A F, Campana G, Simonella A, et al. Determination of chloramphenicol in honey by liquid chromatography-tandem mass spectrometry. Anal Chim Acta, 2005, 529: 257-263

6 Mottier P, Parisod V, Gremaud E, et al. Determination of the antibiotic chloramphenicol in meat and seafood products by liquid chromatography-electrospray ionization tandem mass spectrometry. J Chromatogr A, 2003, 994: 75-84

7 Raz S R, Bremer M G E G, Haasnoot W, et al. Label-free and multiplex detection of antibiotic residues in milk using imaging surface plasmon resonance-based immunosensor. Anal Chem, 2009, 81: 7743-7749

8 Yuan J, Oliver R, Aguilar M I, et al. Surface plasmon resonance assay for chloramphenicol. Anal Chem, 2008, 80: 8329-8333

9 Mohamed R, Richoz-Payot J, Gremaud E, et al. Advantages of molecularly imprinted polymers LC-ESI-MS/MS for the selective extraction and quantification of chloramphenicol in milk-based matrixes. Comparison with a classical sample preparation. Anal Chem, 2007, 79: 9557-9565

10 Gude T, Preiss A, Rubach K. Determination of chloramphenicol in muscle, liver, kidney and urine of pigs by means of immunoaffinity chromatography and gas chromatography with electron-capture detection. J Chromatogr B, 1995, 673: 197-204

11 Leach L M, Ellis M, Sutton D S, et al. The growth performance, carcass characteristics, and meat quality of halothane carrier and negative pigs. J Anim Sci, 74: 934-1996

12 Brambilla G, Cenci T, Franconi F, et al. Clinical and pharmacological profile in a clenbuterol epidemic poisoning of contaminated beef meat in Italy. Toxicol Lett, 2000, 114: 47-53

13 Kuiper H A, Noordam M Y, Van Dooren-Flipsen M M H, et al. Illegal use of beta-adrenergic agonists: European community. J Anim Sci, 1998, 76: 195-207

14 Antignac J P, Marchand P, Bizec L B, et al. Identification of ractopamine residues in tissue and urine samples at ultra-trace level using liquid chromatography-positive electrospray tandem mass spectrometry. J Chromatogr B, 2002, 774: 59-66

15 Shishani E, Chai S C, Jamokha S, et al. Determination of ractopamine in animal tissues by liquid chromatograghy-fluorescence and liquid chromatography/tandem mass spectrometry. Anal Chim Acta, 2003, 483: 137-145

16 Thompson C S, Haughey S A, Traynor I M, et al. Effective monitoring for ractopamine residues in samples of animal origin by SPR biosensor and mass spectrometry. Anal Chim Acta, 2008, 608: 217-225

17 Blanca J, Munoz P, Morgado M, et al. Determination of clenbuterol, ractopamine and zilpaterol in liver and urine by liquid chromatography tandem mass spectrometry. Anal Chim Acta, 2005, 529: 199-205

18 Haasnoot W, Bienenmann-Ploum M, Lamminmaki U, et al. Application of a multi-sulfonamide biosensor immunoassay for the detection of sulfadiazine and sulfamethoxazole residues in broiler serum and its use as a predictor of the levels in edible tissue. Anal Chim Acta, 2005, 552: 87-95

19 Lau J H W, Khoo C S, Murby J E. Determination of clenbuterol, salbutamol, and cimaterol in bovine retina by electrospray ionization-liquid chromatography-tandem mass spectrometry. J AOAC Int, 
2004, 87: 31-38

20 Pfenning A P, Roybal J E, Rupp H S, et al. Simultaneous determination of residues of chloramphenicol, florfenicol, florfenicol amine, and thiamphenicol in shrimp tissue by gas chromatography with electron capture detection. J AOAC Int, 2000, 86: 26-30

21 Zhang H Y, Duan Z J, Wang L, et al. Hapten synthesis and development of polyclonal antibody-based multi-sulfonamide immunoassays. J Agr Food Chem, 2006, 54: 4499-4505

22 Haasnoot W, Bienenmann-Ploum M, Lamminmaki U, et al. Application of a multi-sulfonamide biosensor immunoassay for the detection of sulfadiazine and sulfamethoxazole residues in broiler serum and its use as a predictor of the levels in edible tissue. Anal Chim Acta, 2005, 552: 87-95

23 Shen J Z, Zhang Z, Yao Y, et al. Time-resolved fluoroimmunoassay for ractopamine in swine tissue. Anal Bioanal Chem, 2007, 387: 1561-1564

24 Shen J Z, Zhang Z, Yao Y, et al. A monoclonal antibody-based timeresolved fluoroimmunoassay for chloramphenicol in shrimp and chicken muscle. Anal Chim Acta, 2006, 575: 262-266

25 Kolosova A Y, Samsonova J V, Egorov A M. Competitive ELISA of chloraphenicol: Influence of immunoreagent structure and application of the method for the inspection of food of animal origin. Food Agr Immunnol, 2000, 12: 115-125

26 Wang J P, Zhang S X, Shen J Z. Development of immunoaffinity sample-purification for GC-MS analysis of ractopamine in swine tissue. J Anim Sci, 2006, 84: 1248-1251

27 Ding S Y, Shen J Z, Zhang S X, et al. Determination of chloramphenicol residue in fish and shrimp tissues by gas chromatography with a micrcell electron capture detector. J AOAC Int, 2005, 88: 57-60

Open Access This article is distributed under the terms of the Creative Commons Attribution License which permits any use, distribution, and reproduction in any medium, provided the original author(s) and source are credited. 